Original article

\title{
Development and validation of RP-HPLC method with ultraviolet detection for estimation of montelukast in rabbit plasma: Application to preclinical pharmacokinetics
}

\author{
Om Prakash Ranjan ${ }^{\mathrm{a}}$, Usha Y. Nayak ${ }^{\mathrm{a}}$, Meka Sreenivasa Reddy ${ }^{\mathrm{a}, *}$, Swapnil J. Dengale ${ }^{\mathrm{b}}$, \\ Prashant B. Musmade ${ }^{\text {b }}$, Nayanabhirama Udupa ${ }^{c}$ \\ ${ }^{a}$ Department of Pharmaceutics, Manipal College of Pharmaceutical Sciences, Manipal University, Manipal 576104, Karnataka, India \\ ${ }^{\mathrm{b}}$ Department of Pharmaceutical Quality Assurance, Manipal College of Pharmaceutical Sciences, Manipal University, Manipal 576104, Karnataka, India \\ ${ }^{\mathrm{c}}$ Department of Pharmaceutical Management, Manipal College of Pharmaceutical Sciences, Manipal University, Manipal 576104, Karnataka, India
}

\section{A R T I C L E I N F O}

\section{Article history:}

Received 5 September 2013

Accepted 23 October 2013

Available online 26 November 2013

\section{Keywords:}

Montelukast

Rabbit plasma

HPLC

UV detection

Pharmacokinetics

\begin{abstract}
A B S T R A C T
Objective: To develop a liquid-liquid extraction based reverse phase liquid chromatography method for estimation of montelukast in rabbit plasma.

Methods: Chromatographic separation was carried out using Phenomenex Luna C18 column $(250 \mathrm{~mm} \times 4.6 \mathrm{~mm} \times 5 \mu \mathrm{m})$ with mobile phase composed of ammonium acetate buffer $(20 \mathrm{Mm})$, pH 5.5 and acetonitrile in $20: 80, \mathrm{v} / \mathrm{v}$ ratio. The analyte was monitored with UV detector at $345 \mathrm{~nm}$. The developed method was validated with respect to linearity, accuracy, precision, specificity and stability.

Results: The peak area ratio of montelukast (MKS) to that of internal standard was used for the quantification of samples. Calibration curves were linear in the concentration range of $20-2000 \mathrm{ng} \mathrm{mL}^{-1}$. The LOD and LLOQ of present method were found out to be $10 \mathrm{ng} \mathrm{mL}^{-1}$ and $20 \mathrm{ng} \mathrm{mL}^{-1}$ respectively. The intra-day and inter-day \%CV values for MKS were below $6.06 \%$ and $8.43 \%$. Intra-day and inter-day accuracies were within $95.81 \%$ and $110.90 \%$, respectively. Extraction recoveries of drug from rabbit plasma were $>66.47 \%$. Conclusion: A simple, alternative, reproducible and sensitive HPLC-UV method was developed for MKS that can be used in preclinical pharmacokinetics.
\end{abstract}

Copyright $\odot$ 2013, InPharm Association, Published by Reed Elsevier India Pvt. Ltd. All rights reserved.

\section{Introduction}

Montelukast sodium (MKS) is chemically monosodium salt of [R-(E)]-1-[[[1-[3-[2-(7-chloro-2quinolinyl) ethenyl] phenyl]-3-[2(1-hydroxy-1-methylethyl) phenyl] propyl] thio] methyl] cyclopropaneacetic acid. It is a potent and orally active selective antagonist of the cysteinyl, CysTL1, leukotriene receptor used in management of asthma to children and adults. ${ }^{1}$ A review of literature reveals that number of analytical and bioanalytical methods have been published for quantification of MKS. As long as bioanalysis of MKS is concerned there are great deal of methods ranging from voltammetry ${ }^{2}$ to LC-MS/MS assays ${ }^{3,4}$ have been reported. Amongst all reported bioanalysis assay methods, HPLC analysis with fluorescence detection ${ }^{5,6,7}$ has been tried by many authors by various modifications either in instrumentation part or in sample preparation part. To name few of these modifications are stereo-selective detection with column switching technique. . $^{89}$

After consideration of all published reports regarding bioanalysis of MKS, there are certain common attributes which can

\footnotetext{
* Corresponding author. Tel.: +91 8202922482 (O).

E-mail address: ms.reddy@manipal.edu (M.S. Reddy).
}

easily be cited. Almost all reported methods had preferentially used protein precipitation method for extraction of MKS and fluorescence detector for quantification. As it appeared that, protein precipitation seemed logical choice as long as cost effectiveness is concerned because all methods have been developed for plasma (with smallest processing volume $300 \mu \mathrm{L}$ ) with the aid of sensitive fluorescence detection. All methods except one have been developed for human plasma. While developing the method for human plasma does not need preferential attention towards processing volume because in human pharmacokinetic studies, the sample volume processed for any time point is as much as $1.0 \mathrm{~mL}$. This fact gives the option to negotiate other variables without preference being given to less plasma processing volume.

When posed to estimate the MKS in rodent plasma with intent to build pharmacokinetic profiles, above stated common attributes of published reports turn out to be road blocks. Preclinical studies exclusively demand small amount of blood samples to be collected as blood contained in rodents is less as compared to clinical study samples. If protein precipitation technique mentioned in published reports was to use for sample clean up then it would have been difficult to achieve desired sensitivity by HPLC in preclinical studies. That means, say amount of processing volume to be used is $200 \mu \mathrm{L}$ 
then to precipitate all the proteins in the plasma; it requires volume of precipitating agent 3 times than that of processing volume. In this discussed case it would necessarily dilute the sample to $800 \mu \mathrm{L}$, which eventually would affect the sensitivity of method. Further to add, fluorimetric detector is not standard equipment which come along with HPLC because of its higher cost as compare to UV and as no other method with alternative detection has been mentioned in literature, analyst would be left with no alternative. The objective of present work was to develop alternative and reliable method for quantification of MKS in rabbit plasma that could be applicable to pharmacokinetic studies in terms of less sample volume and very low concentration.

\section{Materials and methods}

\subsection{Reagent and materials}

Montelukast sodium (MKS) sample was obtained from Orchid Pharma, Chennai and internal standard (IS), Lercanidipine HCL, was obtained from Cipla Ltd, Mumbai. Analytical grade reagent such as ammonium acetate was purchased from Merck specialties private limited, Mumbai. HPLC grade reagents such as methanol and acetonitrile were purchased from Merck specialties private limited, Mumbai. Glacial acetic acid (laboratory reagent) was obtained from Himedia Laboratories private limited, Mumbai. Millipore water ( $0.22 \mu \mathrm{m}$ membrane filtered) was produced in the laboratory by Millipore system (Model: Direct- $Q^{\circledR} 3$ water purification system) Millipore Corporation, Billerica, MA, U.S.A.

\subsection{Chromatographic instrumentation}

The analysis was carried out on a Shimadzu LC-2010CHT (Shimadzu Corporation, Kyoto, Japan) equipped with low pressure quaternary gradient pump along with dual wavelength UV detector, column oven, auto sampler and LC solution 1.24SP1 software. Phenomenex Luna C18 column $(250 \mathrm{~mm} \times 4.6 \mathrm{~mm} \times 5 \mu \mathrm{m})$ was used for drug separation. The analyte was monitored with UV detector at $345 \mathrm{~nm}$. A glass vacuum-filtration apparatus (fitted with $0.22 \mu$ filter) were used to filter mobile phase. Ultrasonic bath was used to remove dissolved gases and entrapped air in mobile phase. A model Genie-2 Spinix vortex mixer, a cold centrifugation (Sigma, Germany) were employed during sample processing and TurboVap LV Evaporator (Caliper Life Sciences, Hopkinton, MA, USA) for evaporation purpose after extraction.

\subsection{Chromatographic conditions}

The mobile phase consisting of a mixture of acetonitrile and ammonium acetate buffer $(20 \mathrm{mM}$, pH adjusted to $5.5 \pm 0.02)$ in the ratio $80: 20(\mathrm{v} / \mathrm{v})$ was delivered isocratically at a flow rate of $1.0 \mathrm{~mL} \mathrm{~min}^{-1}$. The chromatographic separation was achieved by a Phenomenex Luna C18 $(250 \mathrm{~mm} \times 4.6 \mathrm{~mm} \times 5 \mu \mathrm{m})$ column. The column temperature, $25{ }^{\circ} \mathrm{C}$ was maintained by a thermostatically controlled column oven. The analyte were quantified at $345 \mathrm{~nm}$ using ultraviolet detection. The run time for each chromatographic analysis was $18.0 \mathrm{~min}$.

\subsection{Preparation of standard solutions}

All standard stock solution and working standard solution were prepared in amber colored volumetric flask. An accurately weighted sample of MKS was dissolved in methanol to give standard stock solution of $100 \mu \mathrm{g} \mathrm{mL}$. Lercanidipine $\mathrm{HCl}$ was used as an internal standard (IS). The working standard solutions were prepared by further serial dilution from the stock solutions with mobile phase mixture.

Calibration standards $(20,50,100,200,500,1000$, $2000 \mathrm{ng} \mathrm{mL}^{-1}$ ) in control rabbit plasma samples were prepared by spiking with $20 \mu \mathrm{L}$ of working stock solutions of MKS. Three quality control (QC) solutions containing low (75 $\mathrm{ng} \mathrm{mL}^{-1}$; LQC), medium (750 ng mL ${ }^{-1}$; MQC) and high (1750 $\left.\mathrm{ng} \mathrm{mL}^{-1} ; \mathrm{HQC}\right)$ were prepared in a similar way. The IS working solutions were prepared providing finally a plasma concentration of $5000 \mathrm{ng} \mathrm{mL}^{-1}$.

\subsection{Sample preparation}

$200 \mu \mathrm{L}$ aliquot of a rabbit plasma sample was spiked with $10 \mu \mathrm{L}$ internal standard solution. Subsequently, sample was extracted with $1.5 \mathrm{ml}$ of tertiary-butyl methyl ether (TBME). The mixture was vortexed for $15 \mathrm{~min}$ and centrifuged at $10,000 \mathrm{rpm}$ for $10 \mathrm{~min}$. After centrifugation, the organic phase was transferred to glass tubes and evaporated to dryness using TurboVap LV Evaporator (Caliper Life Sciences, Hopkinton, MA, USA) at $50{ }^{\circ} \mathrm{C}$ under stream of nitrogen for $5 \mathrm{~min}$. The residue remaining after drying was reconstituted with $150 \mu \mathrm{L}$ of mobile phase mixture and vortexed for $1 \mathrm{~min}$ then a volume of $50 \mu \mathrm{L}$ was injected into the HPLC system.

\subsection{Validation of method}

Validation of the developed method was carried out as per US FDA guidelines for accuracy, precision, linearity, selectivity, sensitivity, reproducibility, and stability. ${ }^{10,11}$

\subsubsection{Selectivity}

The selectivity of method was proved by processing and analyzing blanks prepared from six independent lots of control plasma along with six extracted LOQ-QC samples. ${ }^{12}$ The method is selective if there is no interfering peak present at the retention time of the drug or IS. If there is any interfering peak present at the retention time of drug then its response should be less than $20 \%$ of mean response of six extracted LOQ-QC samples.

\subsubsection{Linearity (calibration curve)}

A calibration (standard) curve is the relationship between instrument response and known concentrations of the analyte. The linearity of developed method was evaluated with a total of three calibration curves over the concentration range $20-2000 \mathrm{ng} \mathrm{mL}^{-1}$ by plotting the peak response (area) ratio of MKS to Lercanidipine $\mathrm{HCl}(y)$ versus concentration of MKS in plasma $(x)$.

\subsubsection{Detection $\mathcal{E}$ quantification limit}

The limit of detection (LOD) is defined as the lowest quantity of substance which gives a peak area of three times the baseline noise. The equation $2 \mathrm{H} / \mathrm{h}$ was used to calculate the ratio of signal size to that of noise. Where, $\mathrm{H}$ is the height of the peak in a chromatogram obtained with the prescribed reference solution and $h$ is the noise in blank chromatogram. ${ }^{12}$ The limit of quantification (LLOQ) was defined as the lowest concentration with ratio of signal-to-noise more than 5 with accuracy of $80-120 \%$ and precision of $20 \%$ to its nominal value.

\subsubsection{Accuracy \& precision}

The different concentrations including lower and upper limits of each QC sample (LOQ-QC, LQC, MQC and HQC) in six replicates were analyzed on the same day and on three different days in order to determine the intra-day inter-day accuracy and precision. ${ }^{11,13}$

The accuracy (\% bias) was calculated as follows:

Accuracy $(\%$ bias $)=\frac{\text { Concentration found }}{\text { Nominal concentration }} \times 100$ 
The percent coefficient of variation, \%CV was calculated as follows:

$\% \mathrm{CV}=\frac{\text { Standard deviation }}{\text { Mean }} \times 100$

The accuracy determined at each concentration level must be within $\pm 15 \%$ except at LOQ-QC where it must not exceed $\pm 20 \%$ of the respective nominal value. The precision around the mean value must not exceed 15\% except for LOQ-QC where it must be within $20 \%$ of the \%CV.

\subsubsection{Recovery}

Recovery is the detector response obtained from an amount of the analyte added to and extracted from the biological matrix, compared to the detector response obtained for the true concentration of standard. It is accessed by comparing the mean peak areas of extracted LQC, MQC and HQC samples to the one obtained after the direct injection of a solution with corresponding concentration (unextracted). ${ }^{11}$

\subsection{Application to preclinical pharmacokinetics}

To assess the applicability of the method, it was used to evaluate the pharmacokinetic of MKS in rabbit. The study was conducted after approval by the Institutional Animal Ethics Committee (IAEC), KMC, Manipal (IAEC/KMC/75/2011-2012). The male rabbits weighing $2.5 \mathrm{~kg}$ were housed with free access to food and water. Rabbits in group $(n=3)^{14,15}$ were dosed orally by gavages with developed immediate release tablet formulation ( $10 \mathrm{mg} /$ tablet). After a single oral administration; $0.6 \mathrm{ml}$ of blood samples were collected from the marginal ear vein ${ }^{16}$ at control and $0.5,1,2,3,4,5,6,7,8,10,12,18$ and $24 \mathrm{~h}$ after the administration into tubes containing EDTA. The plasma was separated immediately using cold centrifugation (Sigma, Germany) at $10,000 \mathrm{rpm}$ for $10 \mathrm{~min}$ and stored at $-70{ }^{\circ} \mathrm{C}$ until analysis.

\section{Results and discussion}

\subsection{Method development}

Due to inherent lipophilicity associated with MKS, which is reflected by very high $\log P$ value i.e. 8.49 , reversed phase was the

Recovery $=\frac{\text { Mean peak area response of extracted samples at LQC, MQC, HQC }}{\text { Mean peak area response of unextracted samples at LQC, MQC, HQC }}$

\subsubsection{Stability studies}

2.6.6.1. Stock solution stability. The drug stability is a function of the storage conditions and the chemical properties of the drug. Stock solution stability was performed at room temperature for $8.0 \mathrm{~h}$ and at $2-8{ }^{\circ} \mathrm{C}$ for 30 days. Stock solution stability was assessed by comparing freshly prepared samples of MKS and IS with that of stability samples at MQC level by performing five injections of each. Mean percentage change was calculated for both MKS and IS. Stock solution of MKS and IS is deemed stable if mean percentage change of IS and MKS was within $\pm 10 \%$.

2.6.6.2. Bench top stability. Six replicates of LQC and HQC in biological matrix were withdrawn and thawed unassisted at room temperature and kept unprocessed for $8 \mathrm{~h}$ (stability samples). After $8 \mathrm{~h}$ fresh calibration was prepared with one set of low and high QC samples (comparison samples).

2.6.6.3. Freeze thaw stability. Freeze thaw stability in plasma was assessed by analyzing six replicates of LQC and HQC samples after three freeze and thaw cycles. Samples were kept at $-70{ }^{\circ} \mathrm{C}$ and frozen for $24 \mathrm{~h}$ and thawed unassisted at room temperature. The freeze-thaw cycle was repeated two more times; samples were then analyzed after the third cycle.

2.6.6.4. Long term stability. Six replicates of LQC and HQC in biological matrix were withdrawn from deep freezer $\left(-70^{\circ} \mathrm{C}\right)$ after 30 days and thawed at room temperature (stability samples). Fresh calibration was prepared with six replicates of low and high QC samples (comparison samples). MKS was deemed stable in matrix if mean percentage change in concentration was within $\pm 15 \%$. logical option for the method development. MKS is a weak base having two pKa values, the first pKa1 is 3.2 which is attributed to ionization of carboxylic acid moiety, while second pKa2 is approximately 6.20 is because of the pyridine ring. This means MKS is prone to ionization at any pH below 3.20 where excess of $\mathrm{H}^{+}$ions would form co-ordinate bonds with nitrogen in the pyridine ring eventually rendering net positive charge. At the same time, MKS would be apt for ionization at any $\mathrm{pH}$ above 6.20 where $\mathrm{H}^{+}$ions from carboxylic acid moiety would start dissociating rendering net negative charge. This behavior of MKS may increase its hydrophilicity with obvious consequence of decrease retention on reverse phase column and poor chromatographic properties above $\mathrm{pH} 6.2$ and below $\mathrm{pH}$ 3.2. According to the Ibrahim et al, MKS is in unionized form at $\mathrm{pH}$ range $4-5 .{ }^{17}$ To improve the retention and chromatographic properties, $\mathrm{pH}$ of the mobile phase was kept 4.5 which ensured that drug would predominantly remain in the unionized form. Ammonium acetate buffer with highest buffer capacity for $\mathrm{pH}$ values in the range of 4.5-6.0 was selected as a buffer component of mobile phase. As a result of high $\log P$ value, it is apparent for MKS to partition predominantly into stationary phase of the reverse phase column [like dissolves like]. Due to this fact, the coefficient of mass transfer in Van Deemter equation plays an important role which further contributes to the poor chromatographic separation and long retention times. ${ }^{18}$ To counter the problem because of the coefficient of mass transfer, there are two ways. First, to decrease the velocity of mobile phase, this gives sufficient time for drug to partition into stationary phase. Second, to increase the elution power of mobile phase by using higher proportion of organic solvents with good elution property. The

Mean percentage change $=\left[\frac{\text { Calculated concentration of stability samples }}{\text { Calculated concentration of comparison samples }}-1\right] \times 100$ 

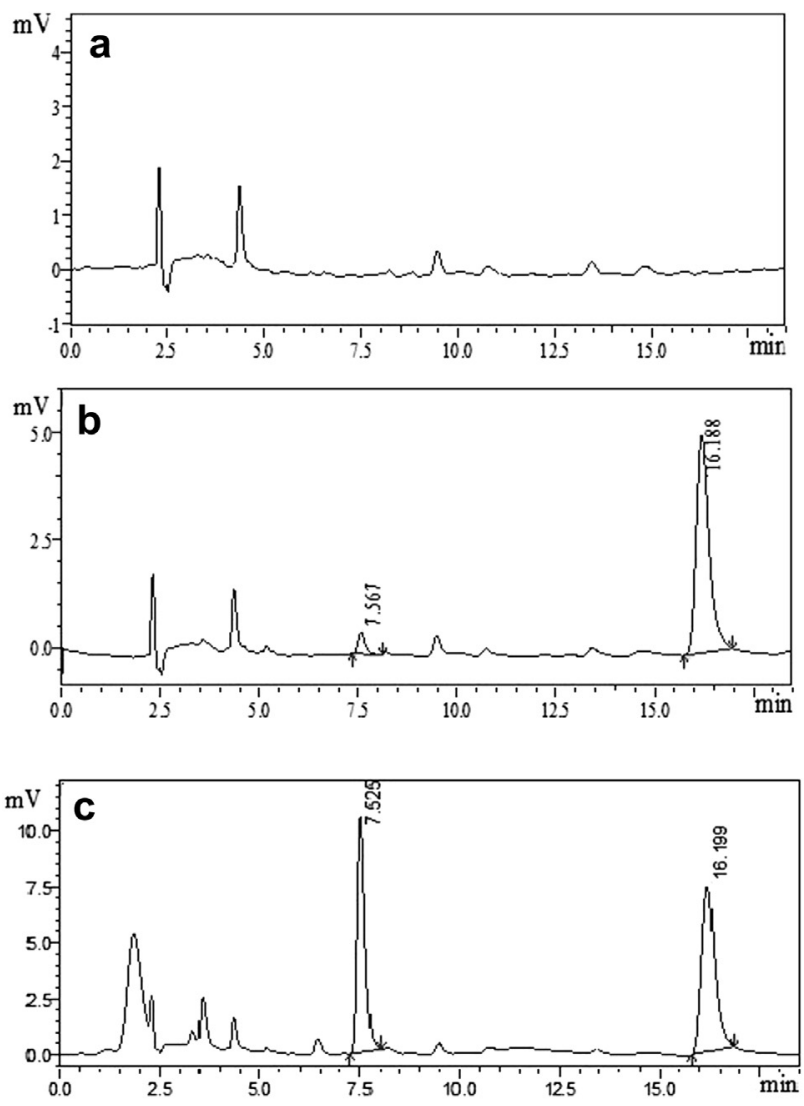

Fig. 1. Representative chromatogram of (a) drug free blank rabbit plasma (b) a rabbit plasma spiked at LQC concentration (c) a rabbit plasma spiked at HQC concentration.

former option does not seem viable as it eventually leads to broader peaks and long retention times. So, later option was adopted during method development by using acetonitrile as a mobile phase component with considerably higher proportions.

Protein precipitation technique was extensively investigated for extraction of MKS from biological matrix in previously published reports. If provided with comparatively less sensitive detector with limited amount of processing volume (which is usually the case in preclinical studies), protein precipitation technique despite of having good recovery faces the problem of sample dilution during extraction, which affects the sensitivity of method adversely. For this reason liquid-liquid extraction was investigated as a sample extraction technique. Due to high $\log \mathrm{P}(8.49)$ value of MKS, various non-polar

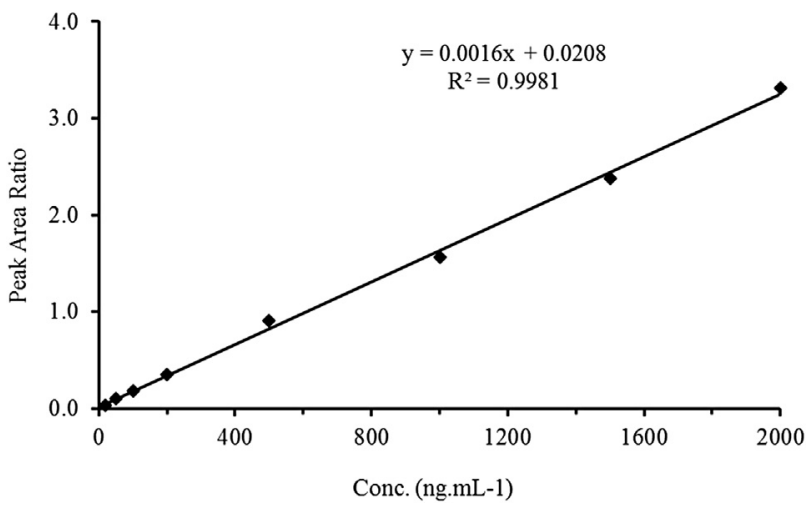

Fig. 2. Calibration curve of MKS in rabbit plasma.
Table 1

Intra-day accuracy and precision data for montelukast at four concentration level $(n=6)$.

\begin{tabular}{lcccl}
\hline QC sample & $\begin{array}{l}\text { Concentration } \\
(\mathrm{ng} / \mathrm{ml})\end{array}$ & $\begin{array}{l}\text { Mean measured } \\
\text { conc. }(\mathrm{ng} / \mathrm{ml}) \pm \mathrm{SD}\end{array}$ & $\begin{array}{l}\text { Accuracy } \\
(\%)\end{array}$ & $\begin{array}{l}\text { Precision } \\
(\% \mathrm{CV})\end{array}$ \\
\hline LLOQC & 20 & $23.18 \pm 1.24$ & 110.9 & 5.59 \\
LQC & 75 & $72.86 \pm 3.27$ & 97.14 & 4.49 \\
MQC & 750 & $742 \pm 43.76$ & 96.33 & 6.06 \\
HQC & 1750 & $1728 \pm 86.51$ & 98.74 & 4.94 \\
\hline
\end{tabular}

Table 2

Inter-day accuracy and precision data for montelukast at four concentration level $(n=6)$.

\begin{tabular}{lclll}
\hline QC sample & $\begin{array}{l}\text { Concentration } \\
(\mathrm{ng} / \mathrm{ml})\end{array}$ & $\begin{array}{l}\text { Mean measured } \\
\text { conc. }(\mathrm{ng} / \mathrm{ml}) \pm \mathrm{SD}\end{array}$ & $\begin{array}{l}\text { Accuracy } \\
(\%)\end{array}$ & $\begin{array}{l}\text { Precision } \\
(\% \mathrm{CV})\end{array}$ \\
\hline LLOQC & 20 & $22.08 \pm 0.84$ & 109.15 & 8.43 \\
LQC & 75 & $71.86 \pm 3.72$ & 95.81 & 5.18 \\
MQC & 750 & $728 \pm 34.67$ & 96.02 & 4.81 \\
HQC & 1750 & $1716 \pm 78.15$ & 97.63 & 4.57 \\
\hline
\end{tabular}

extraction solvents like diethyl ether, n-hexane, TBME and chloroform were tried. Amongst all, TBME showed good recovery and no interference was observed either at drug or IS retention time. $200 \mu \mathrm{l}$ processing volume of rabbit plasma was used which finally concentrated by reconstituting to $100 \mu \mathrm{l}$ volume increasing drug's response.

\subsection{Method validation}

\subsubsection{Selectivity}

The developed method was found selective for both MKS and IS, as no interference was detected at the respective retention times. The representative chromatograms of blank extracted rabbit plasma and spiked rabbit plasma at LQC and HQC concentration are shown in the Fig. 1(a), (b) and (c) respectively.

\subsubsection{Linearity (calibration curve)}

The peak area ratio of standard (MKS) to that of internal standard was used for the quantification of MKS in plasma samples. Calibration curves were linear in the concentration range of 20$2000 \mathrm{ng} \mathrm{mL}^{-1}$ with correlation coefficient $\left(r^{2}\right)$ of 0.9981 (Fig. 2). The mean regression equation was: $y=0.0016 x+0.0208$, Where $y$ is peak area ratio and $x$ is the plasma concentration of MKS.

\subsubsection{Detection and quantification limit}

In alignment with the criteria for clinical and preclinical bioequivalence studies, this demand LLOQ of bioassay to be at least $10 \%$ of the $C_{\max }$ or five $T_{1 / 2}$ of the drug under consideration, whichever is smallest, the LLOQ of present method was found out to be $20 \mathrm{ng} \mathrm{mL}^{-1}$ for the MKS. The LOD considering the signal-tonoise ratio of $3: 1$, was estimated to be $10 \mathrm{ng} \mathrm{mL}^{-1}$.

\subsubsection{Accuracy E' precision}

The intra-day and inter-day accuracy and precision values of the montelukast in rabbit plasma shown in Table 1 and Table 2 respectively' are well within the acceptable limits. The intra-day and inter-day precision (\%CV) values for MKS were below $6.06 \%$

Table 3

Absolute recovery of montelukast $(n=3)$.

\begin{tabular}{lcl}
\hline Sample & Concentration $\left(\mathrm{ng} \mathrm{mL}^{-1}\right)$ & Absolute recovery $($ mean $\pm \mathrm{SD} \%)$ \\
\hline LQC & 75 & $69.58 \pm 2.94$ \\
MQC & 750 & $67.37 \pm 3.06$ \\
HQC & 1750 & $66.47 \pm 4.28$ \\
\hline
\end{tabular}


Table 4

Stability study results for montelukast.

\begin{tabular}{|c|c|c|c|c|c|c|}
\hline \multirow[t]{2}{*}{ Stability } & \multirow{2}{*}{$\begin{array}{l}\text { Spiked concentration } \\
<\left(\text { ng } \mathrm{mL}^{-1}\right)\end{array}$} & \multicolumn{2}{|c|}{ Calculated conc. (comparison sample) } & \multicolumn{2}{|c|}{ Calculated conc. (stability sample) } & \multirow{2}{*}{$\begin{array}{l}\text { Mean } \\
\text { \%change }\end{array}$} \\
\hline & & Mean \pm SD & $\% \mathrm{CV}$ & Mean \pm SD & $\% \mathrm{CV}$ & \\
\hline \multirow[t]{2}{*}{ Bench top } & 75 & $77.46 \pm 2.73$ & 3.52 & $71.64 \pm 2.91$ & 4.06 & -7.51 \\
\hline & 1750 & $1741.21 \pm 67.51$ & 3.88 & $1685.58 \pm 71.23$ & 4.22 & -3.19 \\
\hline \multirow{2}{*}{$\begin{array}{l}\text { Freeze } \\
\text { and thaw }\end{array}$} & 75 & $72.45 \pm 3.11$ & 4.29 & $68.87 \pm 2.95$ & 4.28 & -4.94 \\
\hline & 1750 & $1728.52 \pm 65.38$ & 3.78 & $1681.36 \pm 75.83$ & 4.49 & -2.73 \\
\hline \multirow[t]{2}{*}{ Long term } & 75 & $74.55 \pm 2.47$ & 3.31 & $70.65 \pm 3.27$ & 4.63 & -5.23 \\
\hline & 1750 & $1733.63 \pm 81.17$ & 4.68 & $1673.46 \pm 91.18$ & 5.45 & -3.47 \\
\hline
\end{tabular}

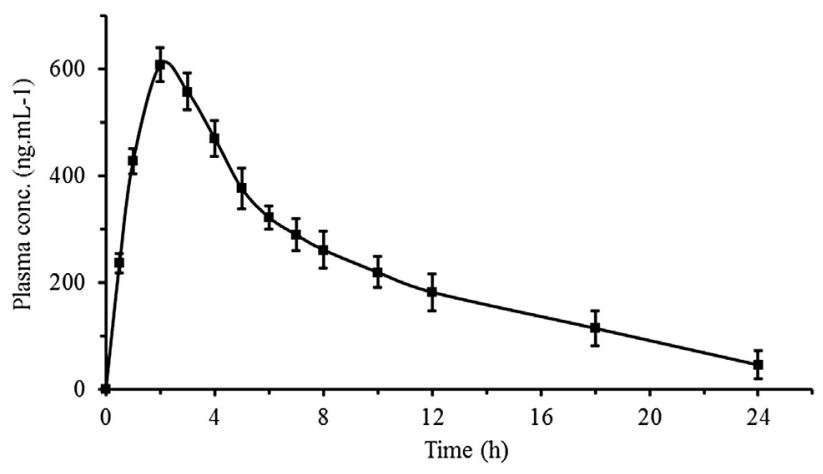

Fig. 3. Mean plasma concentration-time curve after administration of montelukast tablet $(10 \mathrm{mg})$ in rabbits $(n=3)$, values represented as mean \pm SD.

and $8.43 \%$. Intra-day and inter-day accuracies were within $95.81 \%$ and $110.90 \%$, respectively, as acceptable per guidelines.

\subsubsection{Recovery}

The extraction recovery of MKS at LQC, MQC \& HQC is 69.58, 67.37 and $66.47 \%$ respectively (Table 3 ). The extraction recovery was found to be efficient and consistent.

\subsubsection{Stability studies}

The stock solution of MKS was stable at least for $8 \mathrm{~h}$ at room temperature and 30 days when stored at $4{ }^{\circ} \mathrm{C}$, since $\%$ change was found to be less than $10 \%$. Bench top stability of MKS in plasma was investigated at the concentrations of 75 and $1750 \mathrm{ng} \mathrm{mL}^{-1}$ and the results revealed that the MKS in plasma was stable for at least $8 \mathrm{~h}$ at room temperature with an average mean percentage change of -7.15 and $-3.19 \%$ respectively. The repeated freezing and thawing (three cycles) of plasma samples spiked with MKS at two

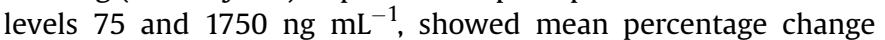
of -4.94 and $-2.73 \%$ respectively. Long term stability of the MKS in plasma at $-70^{\circ} \mathrm{C}$ was also performed after 30 days of storage at two (75 and $1750 \mathrm{ng} \mathrm{mL}^{-1}$ ) levels, which showed mean percentage change of -5.23 and $-3.47 \%$, respectively. The results (Table 4 ) of

Table 5

Pharmacokinetic parameters of montelukast in rabbit $(n=3)$.

\begin{tabular}{ll}
\hline Pharmacokinetic parameters & Montelukast tablet $(10 \mathrm{mg})$ \\
\hline$C_{\max }(\mathrm{ng} / \mathrm{mL})$ & $607.98+29.11$ \\
$T_{\max }(\mathrm{h})$ & 2 \\
$\mathrm{AUC}_{0-\mathrm{t}}(\mathrm{ng} \mathrm{h} / \mathrm{mL})$ & $5438.43 \pm 317.63$ \\
$\mathrm{AUC}_{0-\infty}(\mathrm{ng} \mathrm{h} / \mathrm{mL})$ & $5732.39 \pm 376.83$ \\
$T_{1 / 2}(\mathrm{~h})$ & $4.5 \pm 0.44$ \\
\hline
\end{tabular}

All values are expressed as mean $\pm \mathrm{SD}, n=3, \mathrm{C}_{\max }$ - Maximum plasma concentration; $T_{\max }-$ Time for maximum plasma concentration; $\mathrm{AUC}_{0-\mathrm{t}}$ is the area under the curve from pre-dose to the last sampling time; $\mathrm{AUC}_{0-\infty}$ is the area under the curve from pre-dose extrapolated to infinity; $T_{1 / 2}-$ Elimination half-life. the stability studies indicated that the MKS was stable in the studied conditions.

\section{Application}

The developed method has been used to estimate MKS in plasma after a single oral dosing of $10 \mathrm{mg}$ tablet formulation to rabbits. The mean plasma concentration profile is shown in Fig. 3. The pharmacokinetic parameters are presented in Table 5. After administration of formulation, a peak concentration of $607.98 \pm 29.11 \mathrm{ng} \mathrm{mL}^{-1}\left(C_{\max }\right)$ for montelukast was reached at $2 \mathrm{~h}\left(T_{\max }\right)$. The half-life was found to be $4.5 \pm 0.44 \mathrm{~h}$. Area under plasma concentration $\left(\mathrm{AUC}_{0-\mathrm{t}}\right.$ ) was found to be $5438.43 \pm$ $317.63 \mathrm{ng} \mathrm{h} \mathrm{mL}^{-1}$.

\section{Conclusion}

A simple, alternative, reproducible and sensitive HPLC-UV method was developed for MKS in rabbit plasma. The method was validated over concentration range $20-2000 \mathrm{ng} / \mathrm{ml}$ $\left(r^{2}=0.9981\right)$ and was found to offer good accuracy and precision for monitoring the full pharmacokinetic profile of MKS in individual rodent, like rabbits. The exclusive advantage of the method is the small processing volume used for extraction without jeopardizing the sensitivity. This method can be used to estimate the concentration of MKS in rat and human plasma after performing partial method validation.

\section{Authors contribution list}

1. Mr. Om Prakash Ranjan: Study conception and design, and/or acquisition of data, and/or analysis of data. Drafting the article, and/or revising it critically for important intellectual content.

2. Dr. Usha Y Nayak: Study conception and design, drafting the article, and/or revising it critically for important intellectual content.

3. Dr. M Sreenivasa Reddy: Conception and design, and/or acquisition of data, and/or analysis of data. Drafting the article, and/or revising it critically for important intellectual content.

4. Mr. Swapnil J Dengale: Study conception and design, analysis and interpretation of data, critical revision.

5. Dr. Prashant B Musmade: Drafting the article, critical revision.

6. Dr. Nayanabhirama Udupa: Drafting the article, critical revision.

\section{Conflicts of interest}

All authors have none to declare.

\section{Acknowledgments}

Authors are grateful to acknowledge Manipal College of Pharmaceutical Sciences, Manipal University, Manipal for providing 
infrastructure facility and ICMR, New Delhi, India (Ref. No: 5/4-4/ 49/M/2009-NCD-I) for financial support.

\section{References}

1. Bharathi DV, Hotha KK, Jagadeesh B, Mullangi R, Naidu A. Quantification of montelukast, a selective cysteinyl leukotriene receptor (CysLT1) antagonist in human plasma by liquid chromatography-mass spectrometry: validation and its application to a human pharmacokinetic study. Biomed Chromatogr. 2009;23:804-810.

2. Alsarra I, Al-Omar M, Gadkariem EA, Belal F. Voltammetric determination of montelukast sodium in dosage forms and human plasma. Farmaco. 2005;60: 563-567.

3. Papp R, Luk P, Mullett WM, Kwong E. A rapid and sensitive method for the quantitation of montelukast in sheep plasma using liquid chromatography tandem mass spectrometry. J Chromatogr B Analyt Technol Biomed Life Sci. 2007;858:282-286.

4. Challa BR, Awen BZ, Chandu BR, Khagga M, Kotthapalli CB. Method development and validation of montelukast in human plasma by HPLC coupled with ESI-MS MS: application to a bioequivalence study. Sci Pharm. 2010;78:411-422.

5. Al-Rawithi S, Al-Gazlan S, Al-Ahmadi W, Alshowaier IA, Yusuf A, Raines DA. Expedient liquid chromatographic method with fluorescence detection for montelukast sodium in micro-samples of plasma. J Chromatogr B Biomed Sci Appl. 2001;754:527-531.

6. Kitchen CJ, Wang AQ, Musson DG, Yang AY, Fisher AL. A semi-automated 96well protein precipitation method for the determination of montelukast in human plasma using high performance liquid chromatography/fluorescence detection. J Pharm Biomed Anal. 2003;31:647-654.

7. Sripalakit P, Kongthong B, Saraphanchotiwitthaya A. A simple bioanalytical assay for determination of montelukast in human plasma: application to a pharmacokinetic study. J Chromatogr B Analyt Technol Biomed Life Sci. 2008;869:38-44.
8. Liu L, Cheng H, Zhao JJ, Rogers JD. Determination of montelukast (MK-0476) and its S-enantiomer in human plasma by stereoselective high-performance liquid chromatography with column-switching. J Pharm Biomed Anal. 1997; 15:631-638

9. Ochiai H, Uchiyama N, Takano T, Hara K, Kamei T. Determination of montelukast sodium in human plasma by column-switching high-performance liquid chromatography with fluorescence detection. J Chromatogr B Biomed Sc Appl. 1998;713:409-414.

10. FDAUS. Guidance for Industry. Bioanalytical Method Validation. Rockville, MD, USA: US Department of Health and Human Services, US FDA/Center for Drug Evaluation and Research; 2001.

11. Atifa M, Khalid SH, Onn Kit GL, Sulaiman SAS, Asif M, Chandersekaran A Development and validation of RP-HPLC-UV method for the determination of Glipizide in human plasma. J Young Pharm. 2013;5:26-29.

12. Pathak SM, Kumar AR, Musmade P, Udupa N. A simple and rapid high performance liquid chromatographic method with fluorescence detection for the estimation of fexofenadine in rat plasma-application to preclinical pharmacokinetics. Talanta. 2008;76:338-346.

13. Pathak SM, Musmade PB, Bhat KM, Udupa N. Validated HPLC method for quantitative determination of talinolol in rat plasma and application to a preclinical pharmacokinetic study. Bioanalysis. 2010;2:95-104.

14. Eng J. Sample size estimation: how many individuals should be studied? Radiology. 2003;227:309-313.

15. Charde S, Mudgal M, Kumar L, Saha R. Development and evaluation of buccoadhesive controlled release tablets of lercanidipine. AAPS PharmSciTech. 2008;9:182-190.

16. Parasuraman S, Raveendran R, Kesavan R. Blood sample collection in small laboratory animals. J Pharmacol Pharmacother. 2010;1:87-93.

17. Narin I, Sarioglan S, Anilanmert B, Sari H. pKa determinations for montelukast sodium and levodropropizine. J Solution Chem. 2010;2010:1582-1588.

18. Van deempter JJ, Zuiderweg FJ, Klinkenberg A. Longitudinal diffusion and resistance to mass transfer as causes of nonideality in chromatography. Chem Engng Sci. 1995;50:3869-3882. 